\title{
Faktor Risiko Low Back Pain pada Pekerja Pemetik Teh di Perkebunan Teh Ciater Kabupaten Subang
}

\author{
Ambar Dani Syuhada*), Ari Suwondo**), Yuliani Setyaningsih***) \\ *) Alumni Magister Promosi Kesehatan, Universitas Diponegoro \\ Korespondensi: syuhada.ad@gmail.com \\ **) FKM Universitas Diponegoro
}

\begin{abstract}
ABSTRAK
Low back pain, nyeri yang dirasakan di area anatomi yang terkena dengan berbagai variasi lama terjadinya nyeri. Nyeri ini terasa daerah lumbal atau lumbo-sakral. Pemetik teh berisiko terjadinya low back pain disebabkan kegiatan mereka seperti posisi membungkuk, mengangkat dan membawa beban berat. Tujuan penelitian mengetahui faktor risiko terhadap kejadian low back pain. Jumlah sampel 132 responden: 66 kasus dan 66 kontrol dipilih secara acak dari pekerja pemetik teh. Analisis data menggunakan Chi Square dan Regresi logistik untuk mengatahui faktor yang paling dominan. Ad hubungan masa kerja, postur punggung, berat beban dengan kejadian low back pain $(\mathrm{p}<0.05)$. Tidak ada hubungan umur, jenis kelamin, merokok, indeks masa tubuh dan aktivitas fisik dengan low back pain ( $>0.05$ ). Analisis multivariat menggunaakan regresi logistik menunjukan masa kerja paling dominan berpengaruh terhadap low back pain. Studi ini menemukan bahwa low back pain adalah masalah kesehatan yang relevan di kalangan pekerja pemetik teh. Kebijakan mengatur waktu istirahat dan teknik mengangkat beban diperlukan untuk mencegah low back pain.
\end{abstract}

Kata Kunci: Low back pain, faktor risiko, pemetik teh

\section{ABSTRACT}

Risk factors of low back pain in workers picking tea in Ciater plantation Subang district:

Low back pain, pain that is felt in the affected anatomical area with a variety of long occurrence of pain. This pain feels lumbar or lumbo-sacral. Tea pickers are at risk of low back pain due to their activities such as the position of bending, lifting and carrying heavy loads. This research aim to factors that risk against the incident of low back pain. Total sample of 132 respondents: 66 cases and 66 controls were selected randomly from the tea pickers workers. Data analysis using Chi Square and logistic regression to know the most dominant factor. There was relationship of employment, back posture, heavy weights with low back pain $(P<0.05)$. There was not relationship age, sex, smoking, body mass index and physical activity with low back pain ( $p>0.05)$. Multivariate analysis using logistic regression showed the most dominant working period affecting low back pain. The study found that low back pain was a relevant health problem among tea picker workers. The policy of arranging breaks and lifting techniques is required to prevent low back pain.

Keywords: Low back pain, risk factors, the tea pickers

\section{PENDAHULUAN}

Low back pain atau nyeri punggung bawah, nyeri yang dirasakan di punggung bagian bawah, bukan merupakan penyakit ataupun diagnosis untuk suatu penyakit namun merupakan istilah untuk nyeri yang dirasakan di area anatomi yang terkena dengan berbagai variasi lama terjadinya nyeri. Nyeri ini terasa diantara sudut iga terbawah sampai lipat pinggul bawah yaitu di daerah lumbal atau lumbo-sakral, nyeri dapat menjalar hingga ke arah tungkai dan kaki.(Ehrlich, 2003). 
Low back pain dapat disebabkan oleh berbagai penyakit muskuloskeletal, gangguan psikologis dan mobilisasi yang salah. (Duthey, 2013) Terdapat beberapa faktor risiko penting yang terkait dengan kejadian low back pain yaitu usia diatas 35 tahun, perokok, masa kerja 5-10 tahun, posisi kerja, kegemukan dan riwayat keluarga penderita musculoskeletal disorder. (Astuti, 2007) Faktor lain yang dapat mempengaruhi timbulnya gangguan low back pain meliputi karakteristik individu yaitu indeks massa tubuh (IMT), tinggi badan, stres kerja, masa kerja, posisi kerja dan beban angkat. (Harrrianto, 2007). Berat beban yang diangkat, frekuensi angkat serta cara atau teknik mengangkat beban sering dapat mempengaruhi kesehatan pekerja berupa kecelakaan kerja ataupun timbulnya nyeri atau cedera pada punggung.(Effendi, 2007).

Berdasarkan Institute of Medicine Report from the Committee on Advancing Pain Research, Care, and Education tahun 2011 Total biaya tambahan tahunan perawatan kesehatan karena nyeri dari $\$ 560.000 .000 .000$ menjadi \$635.000.000. 000 di Amerika Serikat. Diperkirakan 20\% dari orang dewasa Amerika (42 juta orang) melaporkan bahwa rasa sakit atau ketidaknyamanan fisik mengganggu tidur mereka beberapa malam dalam seminggu atau lebih. National Institute of Health Statistics survey menunjukkan bahwa terdapat 4 keluhan nyeri yang dirasakan yaitu nyeri punggung (27\%), diikuti oleh sakit kepala berat atau sakit migrain (15\%), nyeri leher (15\%) dan sakit wajah atau sakit (4\%). Sakit punggung adalah penyebab utama kecacatan di Amerika di bawah 45 tahun. Lebih dari 26 juta orang Amerika antara usia 20-64 pengalaman sering sakit punggung. (American Academy of Pain Medicine, 2011).

Berdasarkan data Jamsostek tahun 2013 kasus kecelakaan kerja rata-rata tumbuh $1,76 \%$ setiap tahunnya dan sebagian besar korban dari kasus tersebut kembali sembuh. Pada tahun 2013 terjadi 103.285 kasus kecelakaan kerja, atau ratarata terjadi 283 kecelakaan kerja setiap hari, dengan korban meninggal rata-rata 7 orang, cacat 18 orang dan sisanya kembali sembuh. (Jamsostek, 2013) Hasil Riskesdas 2013 menunjukan 11,0\% pekerja mengalami gangguan pendengaran dan $11,9 \%$ mengalami penyakit sendi otot, serta $52,8 \%$ masyarakat memiliki kebiasaan aktifitas yang kurang, 21,2\% memiliki kebiasaan merokok dan hanya $10,7 \%$ yang memiliki kebiasaan mengkonsumsi sayur dan buah setiap hari. (Direktorat Bina Kesehatan Dan Olahraga, 2014). Hasil studi pendahuluan yang dilakukan oleh peneliti dari data kunjungan rawat jalan Balai pengobatan perkebunan Ciater Kabupaten Subang yang mengalami low back pain pada tahun 2014 sebesar 
$5,7 \%$ dari 1.680 pasien dan terjadi peningkatan kasus pada tahun 2015 sebesar 12\% dari 1.702 pasien. Maka penelitian ini bertujuan menganalisis hubungan antara faktor umur, jenis kelamin, masa kerja, status merokok, indeks masa tubuh, aktivitas fisik, postur punggung dan berat beban dengan low back pain pada pekerja pemetik teh perkebunan Ciater Kabupaten Subang.

\section{METODE}

Jenis penelitian yang digunakan dalam penelitian ini adalah penelitian observasional analitik dengan desain case control atau kasus kontrol yaitu suatu penelitian yang mempelajari faktor risiko dengan menggunakan pendekatan retrospektif. Tempat penelitian dilaksanakan di PT. X perkebunan Ciater Kabupaten Subang pada tahun 2016. Populasi dalam penelitian ini adalah semua pekerja pemetik teh sebanyak 689 orang, populasi kasus sebanyak 205 orang. Jumlah sampel yang diteliti sebanyak 132 orang yang terdiri dari 66 kelompok kasus dan 66 kelompok kontrol. Cara pengambilan sampel menggunakan random sampling.

Instrument pengumpulan data pada penelitian ini menggunakan kuesioner pengambilan data variabel bebas yaitu faktor individu (umur, jenis kelamin, masa kerja, merokok, indeks masa tubuh, aktivitas fisik) dan faktor pekerjaan (postur pungung, berat beban). Data low back pain berdasarkan hasil rekamedis poliklinik dan rumah sakit. Hasil penelitian dianalisis secara univariat, bivariat dan multivariat. Analisis bivariat menggunakan chi square sedangkan anlisis multivariat menggunakan regresi logistik.

\section{HASIL DAN PEMBAHASAN}

\section{Analisis bivariat}

Umur responden dalam penelitian ini antara 22-62 tahun dengan rata-rata umur respoden 44,21 tahun. Pekerja berjenis kelamin perempuan jumlah yang paling banyak yaitu sebesar 59,1\%. Masa kerja responden 1-40 tahun, rata-rata masa kerja respoden 21,52 tahun. Responden yang mempunyai kebiasaan merokok sebesar $35,6 \%$. Indeks masa tubuh paling rendah $16,7 \mathrm{~kg} / \mathrm{m}^{2}$ dan indeks masa tubuh paling tinggi $27,3 \mathrm{~kg} / \mathrm{m}^{2}$ Rata-rata indeks masa tubuh respoden $21,174 \mathrm{~kg} / \mathrm{m}^{2}$. Aktivitas fisik responden yang paling banyak terdapat pada kelompok kategori ringan yaitu sebesar $69,7 \%$. postur punggung tidak normal (lebih dari $20^{\circ}$ dari garis vertikal) sebesar $62,1 \%$. Berat beban yang diangakat antara $2-13 \mathrm{~kg}$. Rata-rata berat beban yang diangkat respoden $5,31 \mathrm{~kg}$ 
Tabel 1. Analisis bivariat antara variabel independen dengan variabel dependen

\begin{tabular}{|c|c|c|c|c|c|}
\hline \multirow[b]{2}{*}{ Variabel } & \multirow[b]{2}{*}{$\mathbf{N}(\%)$} & \multicolumn{2}{|c|}{ Low Back Pain } & \multirow{2}{*}{$\begin{array}{l}\text { OR } \\
(95 \% \mathrm{CI})\end{array}$} & \multirow[b]{2}{*}{$P$} \\
\hline & & $\begin{array}{l}\text { Kasus } \\
(\%)\end{array}$ & $\begin{array}{l}\text { Kontrol } \\
(\%)\end{array}$ & & \\
\hline \multicolumn{6}{|l|}{ Umur } \\
\hline$\geq 35$ tahun & $118(89,4)$ & $58(87,9)$ & $60(90,9)$ & $0,725(0,237-2,218)$ & 0,777 \\
\hline$<35$ tahun & $14(10,6)$ & $8(12,1)$ & $6(9,1)$ & & \\
\hline \multicolumn{6}{|l|}{ Jenis kelamin } \\
\hline Perempuan & $78(59,1)$ & $40(60,6)$ & $38(57,6)$ & $1,134(0,566-2,270)$ & 0,859 \\
\hline Laki-laki & $54(40,9)$ & $26(39,4)$ & $28(42,4)$ & & \\
\hline \multicolumn{6}{|l|}{ Masa kerja } \\
\hline$>10$ tahun & $110(83,3)$ & $60(90,9)$ & $50(75,8)$ & $3,200(1,165-8,791)$ & $0,036^{*}$ \\
\hline$\leq 10$ tahun & $22(16,7)$ & $6(9,1)$ & $1624,2)$ & & \\
\hline
\end{tabular}

Status merokok

Merokok

Tidak merokok

Indeks masa tubuh

Obesitas

Tidak obesitas

Aktivitas fisik

$$
\text { Ringan }
$$

Berat

Postur punggung

Tidak normal

Normal

Berat beban

$>5 \mathrm{~kg}$

$49(37,1)$

$31(47,0)$

$18(27,3)$

$2,362(1,143-4,882)$

$0,031 *$

$\leq 5 \mathrm{~kg}$

$83(62,9)$ $48(72,7)$

Ket: $* p<0,05$

Tabel 1 menunjukan hasil analisis bivariat. Pekerja yang berumur $\geq 35$ tahun mengalami low back pain pada kelompok kasus sebanyak 87,9\%. Sebanyak $90.9 \%$
Pekerja yang memiliki masa kerja >10 tahun mengalami low back pain. Pekerja dengan postur punggung tidak normal mengalami low back pain pada kelompok 
kasus sebanyak 72,7\%. Pekerja mengangkat berat beban $>5 \mathrm{~kg}$ mengalami low back pain pada kelompok kasus sebanyak 47,0\%. Berdasarkan hasil analisis bivariat menyatakan bahwa masa kerja, postur punggung dan berat beban berhubungan dengan low back pain. $(\mathrm{p}<0,05)$ Sedangkan jenis kelamin, merokok, indeks masa tubuh dan aktifitas fisik tidak ada hubunga dengan low back pain $(\mathrm{p}>0,05)$.

Masa kerja merupakan kurun waktu atau lamanya tenaga kerja bekerja di suatu tempat. Masa kerja dapat mempengaruhi tenaga kerja baik positif maupun negatif akan memberikan pengaruh positif kepada tenaga kerja bila dengan lamanya seseorang bekerja maka dia akan semakin berpengalaman dalam melakukan tugasnya. Sebaliknya akan memberikan pengaruh negatif apabila semakin lamanya seseorang bekerja maka akan menimbulkan kebosanan dan kelelahan kerja yang berujung pada kerusakan organ tubuh.(Budiono, 2003)

Posisi tubuh dalam kerja sangat ditentukan oleh jenis pekerjaan yang berbeda-beda terhadap tubuh. Masingmasing posisi kerja memiliki pengaruh yang berbeda-beda terhadap tubuh.(Tarwaka dkk, 2004). Hasil penelitian menyatakan bahwa pekerja dengan postur punggung tidak normal pada saat bekerja mempunyai risiko 2,5 kali lebih tinggi mengalami low back pain di bandingkan dengan pekerja yang postur punggung normal pada saat bekerja.

Berdasarkan penelitian (Widjaya et all, 2012) bahwa ada hubungan antara sikap dan posisi kerja dengan kejadian low back pain dengan nilai $P=0,00$. Dwiyono juga menyatakan hal yang sama bahwa terdapat hubungan antara postur tubuh dengan kejadian muskulosceletal disorders segmen pinggang bawah dengan OR 7,01. Pekerja dengan postur janggal berisiko 1,3 kali di banding dengan postur normal. Aktivitas fisik yang berat dan postur kerja canggung berhubungan dengan peningkatan risiko disc degenerasi, osteofit,

dan osteoarthritis. (Meucci et al., 2015). Posisi memetik dengan cara membungkuk merupakan kegiatan yang statis dan dilakukan secara terus menerus selama 5-7 jam dengan memikul berat beban hasil petikan daun teh. Pada sikap kerja yang statis, peredaran darah ke otot berkurang sehingga glukosa dan oksigen ke otot menjadi terhambat dan harus menggunakan cadangan yang ada dan sisa metabolisme tidak bisa dibuang. Oleh karena itu, otot yang bekerja statis akan terasa nyeri dan langsung menjadi lelah.(Budiono, 2005).

Pekerja yang mengangkat berat beban $>5 \mathrm{~kg}$ pada saat bekerja mempunyai risiko 2,3 kali lebih tinggi mengalami low back pain di bandingkan dengan pekerja 
yang mengangkat beban $\leq 5 \mathrm{~kg}$. Pembebanan yang berlebih bagi pekerja terlebih dengan posisi tempat penyimpanan teh (keranjang) terletak pada punggung selama 5-7 jam, pekerja dalam sehari memperolah total hasil petikan dengan berat rata-rata $59 \mathrm{~kg}$ dan berat maksimal yang di peroleh dalam satu hari mencapai $80 \mathrm{~kg}$. Pekerja harus memindahkankan hasil petikan dengan cara di gendong dari lokasi penyimpanan sementara menuju tempat penimbangan yang berjarak sekitar $50 \mathrm{~s} / \mathrm{d} 100$ meter.

Hasil penelitian ini sejalan dengan Aghilinejad menunjukan bahwa ada hubungan yang signifikan berat beban dengan kronisitas LBP, mengangkat beban lebih dari $15 \mathrm{~kg}$ berisiko 2,4 kali terjadinya low back pain $(\mathrm{OR}=2,482)$. (Aghilinejad, 2015). Membawa, mengangkat, atau memindahkan bahan berat secara signifikan berhubungan dengan nyeri punggung $(\mathrm{OR}=2.74)$. (Rosecrance and Rodgers, 2006). Akibat dari beban yang terlalu berat ataupun kemampuan fisik yang terlalu lemah dapat mengakibatkan seseorang pekerja menderita gangguan atau penyakit akibat kerja. Ada beberapa bukti bahwa semakin banyak jumlah material yang diangkat (dan dipindahkan) dalam sehari oleh seseorang, maka akan lebih cepat mengurangi ketebalan dari intervertebral disc atau elemen yang berada diantara segmen tulang belakang.(Nurmantio, 1996)

\section{Analisis Multivariat}

Tabel 2 Hasil Uji Statistik Multivariat

\begin{tabular}{llllll}
\hline Variabel & B & P value & $\operatorname{Exp}(\mathrm{B})$ & \multicolumn{2}{l}{$95 \% \mathrm{CI}$} \\
\cline { 5 - 6 } & & & & Lower & Upper \\
\hline Postur punggung & 0,760 & 0,053 & 2,138 & 0,991 & 4,613 \\
Masa kerja & 1,213 & $0,023^{*}$ & 3,365 & 1,182 & 9,580 \\
Berat beban & 0,703 & 0,076 & 2,020 & 0,930 & 4,387 \\
Constant & $-0,920$ & & & & \\
\hline
\end{tabular}

Ket: $* p<0,05$

Hasil analisis multivariat menyatakan bahwa pekerja pemetik teh dengan masa kerja >10 tahun mempunyai resiko 3,2 kali terjadinya low back pain dibandingkan dengan pekerja dengan masa kerja $\leq 10$ tahun. Hasil perhitungan probabilitas sebesar $68 \%$ artinya masa kerja $>10$ tahun akan memiliki probabilitas untuk terjadinya low back pain sebesar $68 \%$, sedangkan sisanya sebesar $32 \%$ kemungkinan disebabkan oleh faktor lain yang tidak diteliti dalam penelitian ini 
seperti genetik, status kesehatan yang berkaitan dengan tulang rangka, suhu dan psikososial. Masa kerja dan lamanya bekerja setiap hari akan mempunyai potensi lebih besar untuk terjadinya penyaki akibat kerja. Masa kerja merupakan salah satu faktor yang mempengaruhi pekerja untuk terkena penyakit akibat kerja. Semakin lama pekerja bekerja di tempat kerja, maka semakin besar kemungkinan mereka terpapar oleh faktor-faktor di lingkungan kerja yang dapat menimbulkan gangguan kesehatan atau penyakit akibat kerja. Hal ini dapat mengakibatkan menurunnya efisiensi dan produktivitas kerja seseorang.(Wahyu, 2003).

Seperti halnya yang dinyatakan oleh Min et al. bahwa nyeri punggung bawah lebih sering pada mereka dengan lama bertani lebih dari 30 tahun. Petani yang lama bertani lebih dari 30 tahun mempunyai risiko 1,4 kali berisiko terjadi low back pain dibandingkan dengan petani yang lama bertani kurang dari 30 tahun hal ini disebabkan petani yang berusia tua mempunyai masa kerja yang lama.(Min, 2016) Menurut OSHA gangguan pada otot muncul 2 tahun setelah bekerja dengan jenis pekerjaan yang sama. Pekerjaan yang sama merupakan pekerjaan yang menggunakan otot yang sama dalam waktu yang lama atau lebih dari 2 jam. Asam laktat menumpuk disebabkan yang berlangsung secara metabolisme anaerob. Hal ini terjadi karena aliran darah kurang lancar yang mengakibatkan risiko nyeri punggung bawah lebih tinggi.(Wicaksono, 2014)

Penelitian ini juga di perkuat oleh (Puntumetakul et al., 2015) bahwa masa kerja sebagai petani mempunyai hubungan yang signifikan dengan clinical lumbar instability $(P=0.05)$. Pekerja yang mempunyai masa kerja $\geq 30$ tahun berisiko 2 kali lebih tinggi untuk terjadinya clinical lumbar instability dibandingkan dengan masa kerja <30 tahun. Pembebanan kumulatif jangka panjang dan cedera jaringan secara berulang menghasilkan beban mekanis tidak normal dan mengakumulasi regangan yang berulang pada lumbar tulang belakang.

Hasil penelitian ini sesuai dengan (Umami et al., 2014) bahwa masa kerja berhubungan signifikan dengan keluhan low back pain $(p=0,00)$, pekerja yang banyak mengalami keluhan nyeri punggung bawah adalah yang mempunyai masa kerja >10 tahun dan yang paling banyak mengalami keluhan sakit punggung pada tingkat nyeri sedang. Hal yang sama juga di nyatakan (Putri AS , Saftarina F, 2010) bahwa ada hubungan antara masa kerja dengan kejadian low back pain ( $p=$ $0,001)$ dari 42 responden didapatkan data responden masa kerja lebih dari 10 tahun $42,9 \%$ dan data paling sedikit pada masa 
kerja kurang dari 5 tahun sebanyak 19,0\%. Pada hasil penilaian masa kerja tersebut, responden cenderung bekerja dengan masa kerja yaitu lebih dari 10 tahun dengan ratarata bekerja 8-9 jam dalam sehari.

Gerakan berulang yang konstan memberikan beban kerja secara kumulatif, dapat menyebabkan rasa sakit yaitu gangguan fungsi otot dan jaringan lunak lainnya. Masalah yang timbul dari pekerjaan berulang atau tekanan otot berlebihan yaitu kelelahan otot, perubahan kepadatan jaringan, dan ketegangan jaringan. bukti fisiologis menunjukkan bahwa tingkat dan derajat kerusakan jaringan tergantung pada jumlah kekuatan, pengulangan dan durasi paparan.(Pal Amitava et al, 2014)

Menurut (Geller, 2001) faktor pengalaman pada tugas yang sama dan lingkungan sudah dikenal dapat mempengaruhi orang tersebut berperilaku tidak aman dan terus berlaku karena menyenagkan, nyaman, dan menghemat waktu dan perilaku ini cenderung berulang. Pekerja yang sudah lama cenderung lebih percaya diri karena merasa telah mengenal seluk beluk perusahaan dan terbiasa sehingga menganggap remeh bahaya yang ada. Pekerja yang lama akan merasa lebih berpengalaman sehingga mereka merasa tidak asing dengan pekerjaan dan lingkungan tempat kerja, perilaku yang meremehkan menjadi kurang berhati-hati dalam bertindak. Jenis pekerjaan yang monoton menyebabkan beban kerja fisik, beban kerja fisik dapat mengakibatkan kelelahan pada pekerja sehingga apabila pekerja dalam kondisi lelah dan tetap bekerja maka akan berakibat pekerja mengalami keluhan-keluhan sakit seperti keluhan otot skeletal.(Umami et al., 2014)

\section{SIMPULAN}

Masa kerja >10 tahun mempunyai risiko 3,2 kali lebih besar mengalami low back pain dibandingkan dengan masa kerja $\leq 10$ tahun, postur tidak normal pada saat bekerja mempunyai resiko 2,5 kali lebih besar berpotensi mengalami low back pain dibandingkan dengan postur tubuh normal, mengangkat beban lebih berat $>5 \mathrm{~kg}$ berisiko 2,3 kali lebih besar mengalami low back pain dibandingkan dengan mengangkat berat $<5 \mathrm{~kg}$. Faktor yang paling dominan yang mempengaruhi low back pain secara bersama-sama yaitu masa kerja, dengan nilai probabilitas sebesar $68 \%$.

\section{KEPUSTAKAAN}

Aghilinejad, M. et all, 2015. The effect of Physical and Psychosocial Occupational Factors on The Chronicity of Low Back Pain in The Workers of Iranian Metal industry : a cohort study. Med. J. Islam. Repub. Iran 29, 242. 
American Academy of Pain Medicine, 2011. Facts and Figures on Pain [WWW Document]. Am. Acad. Pain Med.

URL www.painmed.org/patientcenter/factson-pain/ (accessed 12.1.16).

Astuti, R.D., 2007. Aktivitas Kerja Dan Beban Angkat. Scholar 28.

Budiono, 2005. Bunga rampai Hegiene Perusahaan dan KK, 2nd ed. Universitas Diponegoro Semarang, Semarang.

Budiono, dkk, 2003. Hiperkes dan KK. Tri Tunggal Tata Fajar, Surakarta.

Direktorat Bina Kesehatan Dan Olahraga, D.J.B.G. dan K.K.K., 2014. Pedoman Pos Upaya Kesehatan Kerja Terintegrasi.

Duthey, B., 2013. Background Paper 6.24 Low back pain. Priority Medicines for Europe and the World. Glob. Burd. Dis. 1-29.

Effendi, F., 2007. Ergonomi Bagi Pekerja

Sektor Informal. Cermin Dunia Kedokt. 34, 9.

Ehrlich, G.E., 2003. Low back pain. Bull. World Health Organ. 81, 671-676.

Geller, E. scoot, 2001. The Pshychology Of Safety Handbook. Lewis Publisher, USA.

Harrrianto, 2007. Buku Ajar Kesehatan Kerja. EGC, Jakarta.

Jamsostek, 2013. laporan Tahunan 2013, Memperkokoh Landasan bpjs
Ketenagakerjaan.

Meucci, R.D., Fassa, A.G., Faria, N.M.X., Fiori, N.S., 2015. Chronic low back pain among tobacco farmers in southern Brazil. Int. J. Occup. Environ. Health 21, 66-73. doi:10.1179/2049396714Y.00000000 94

Min, D. et all, 2016. Prevalence and Characteristics of Musculoskeletal Pain in Korean Farmers. Ann. Rehabil. Med. 40, 1-13. doi:10.5535/arm.2016.40.1.1

Nurmantio, E., 1996. Ergonomi Konsep Dasar dan Aplikasinya, 1 st. ed. Candimas Metropole, Jakarta.

Pal Amitava et al, 2014. Ergonomic Evaluation of Work Related Musculoskeletal Disorders and Postural Stress among Male Potato Cultivators of West Bengal. Int. J. Occup. Saf. Heal. 4, 5-14.

Puntumetakul, R., Yodchaisarn, W., Emasithi, A., Keawduangdee, P., Chatchawan, U., Yamauchi, J., Press, D., 2015. Prevalence And Individual Risk Factors Associated With Clinical Lumbar Instability In Rice Farmers With Low Back Pain. Patient Prefer. Adherence $\quad 9, \quad 1-7$. doi:10.2147/PPA.S73412

Putri AS , Saftarina F, W.R., 2010. Correlation Between Working Period and Working Position with the 
Incidence of Low Back Pain ( LBP )

in Cleaning Workers of Onion Shell at

Unit Dagang Bawang Lanang

Iringmulyo Metro City. Fac. Med.

Lampung Uni 35-41.

Rosecrance, J., Rodgers, G., 2006. Low

Back Pain and Musculoskeletal

Symptoms Among Kansas Farmers

556 ,

547-556.

doi:10.1002/ajim.20324.

Tarwaka dkk, 2004. Ergonomi Untuk

Keselamatan, Kesehatan Kerja Dan

Produktivitas. UNIBA Press,

Surakarta.

Umami, A.R., Hartanti, R.I., Sujoso,

A.D.P., 2014. Hubungan antara

Karakteristik Responden dan Sikap

Kerja Duduk dengan Keluhan Nyeri

Punggung Bawah (Low Back Pain)

Pada Pekerja Batik Tulis (The
Relationship Among Respondent

Characteristic and Awkward Posture with Low Back Pain in Batik Workers). Pustaka Kesehat. 2, 72-78. Wahyu, A., 2003. Higiene Perusahaan. Bagian Kesehatan dan Keselamatan Kerja FKM UNHAS, Makasar.

Wicaksono, B., 2014. Faktor Yang Berhubungan Dengan Gangguan Nyeri Punggung Bawah Pada Bidan Saat Menolong Proses Persalinan. Indones. J. Saf. Heal. Environtment 1. doi:10.1002/ejoc.201200111

Widjaya et all, 2012. Faktor-faktor Yang Berhubungan Bengan Kejadian Low Back Pain Pada Pekerja Furniture 8590. 